\title{
Growth Inhibition of Nano WC particles in WC-Co Alloys during Liquid-Phase Sintering
}

\author{
Osung Seo ${ }^{1}$, Shinhoo Kang ${ }^{1}$ and Enrique J. Lavernia ${ }^{2}$ \\ ${ }^{1}$ School of Materials Science \& Engineering Seoul National University, Seoul, 151-742, Korea \\ ${ }^{2}$ Department of Chemical and Biochemical Engineering and Materials Science, University of California, Irvine, 92697, USA
}

\begin{abstract}
WC-10Co- $x$ VC alloys were produced using two different sizes of WC powders $(200 \mathrm{~nm}$ and $4.4 \mu \mathrm{m})$ via planetary milling and a liquidphase sintering technique. When VC was added to the WC-Co alloys, the growth of WC particles was effectively suppressed. However, this process was dependent on the amount of additive used. Since the average WC particle size became less than $1 \mu \mathrm{m}$, the system experienced a significant loss in carbon, resulting in the formation of an undesirable $\eta$ phase. The goal of this study was to determine the role of VC in controlling growth and to verify its effectiveness as a function of average WC size and inhibitor content. It was found from XRD and HREM studies that the $(\mathrm{W}, \mathrm{M}) \mathrm{C}$ phase was formed in WC-10Co- $x \mathrm{VC}-\mathrm{C}$ systems. The effect of $\mathrm{V}$ or VC on the solubility of W in the Co matrix was also examined using HREM/EDS. The findings indicate that the presence of VC tends to reduce the solubility of W in a Co melt, thus inhibiting the dissolution and growth of WC.
\end{abstract}

(Received July 10, 2003; Accepted September 12, 2003)

Keywords: nano-tungsten carbide particles, growth inhibition, tungsten carbide cobalt alloys, liquid-phase sintering

\section{Introduction}

The performance of a cutting tool is usually evaluated in terms of both its accuracy and productivity in industrial applications. WC-Co materials are known to be superior for use as cutting tools due to their excellent performance and mechanical properties over a broad range of applications. Although the availability of other materials for use in cutting tools has increased in the cutting tool market, the demand for hard WC-Co materials continues to remain strong since the development of the Schroter method (1923) and production by Widia. ${ }^{1)}$

To promote the efficiency of WC-Co, recent research has been focused on three areas. The first involves improving mechanical properties via the use of fine sized WC particles along with carbon as a control. A smaller grain size would simultaneously increase hardness and toughness through appropriate processing techniques. The second involves a surface coating with a hard phase such as TiN or diamond on the WC-Co to increase wear resistance and tool lifetime. The third involves the addition of other materials to improve corrosion and improve resistance to oxidation. ${ }^{2-5)}$

Of the above issues, research directed at WC-Co prepared using nano sized WC particles has experienced some progress in recent years. Compared with a WC-Co system in which micron-sized WC is used, a higher degree of hardness can be achieved because of the nano grain size as well as by strengthening the binder itself by increasing the quantity of dissolved W. ${ }^{6}$ In addition, the decrease in hardness as the result of an increase in binder content is less severe in a system where submicron-sized WC is used than in micron-sized ones. ${ }^{7)}$ Hardness can be further improved by the addition of various secondary carbides such as TiC, $\mathrm{VC}, \mathrm{TaC}$ or $\mathrm{Cr}_{3} \mathrm{C}_{2}{ }^{8-10)}$

VC and $\mathrm{Cr}_{3} \mathrm{C}_{2}$ are typically used in WC-Co alloys to control particle coarsening in a fine microstructure, which can be obtained by the use of ultra-fine or nano-sized raw powders. However, the addition of an excess of $\mathrm{VC}$ leads to the formation of a meta-stable phase of $\eta\left(\mathrm{Co}_{3} \mathrm{~W}_{3} \mathrm{C}\right)$ which is detrimental to overall performance. ${ }^{11,12)}$ The presence of $\mathrm{Cr}_{3} \mathrm{C}_{2}$ in the system also provides increased mechanical properties along with a more refined microstructure. However the effect of a small amount of added $\mathrm{Cr}_{3} \mathrm{C}_{2}$ is regarded small to that VC. The addition of a large amount of VC leads to the formation of an $\mathrm{M}_{7} \mathrm{C}_{3}$-type carbide, resulting in the degradation of mechanical properties. ${ }^{13)}$

A few studies have been reported on the inhibition of growth of WC fine particles in WC-Co systems. One of the proposed mechanisms involves the formation of $(\mathrm{V}, \mathrm{W}) \mathrm{C}$ and the $\eta$ phase in WC-Co-VC. ${ }^{14)}$ The other relates to the segregation of vanadium at the $\mathrm{WC} / \mathrm{Co}$ interface to inhibit growth. ${ }^{15,16)}$ However, none of those mechanisms clearly explains the growth inhibition or the roles of $\mathrm{VC}$ and $\mathrm{Cr}_{3} \mathrm{C}_{2}$. The goal of this study was to develop a better understanding of the process by which some phases are formed and subsequently to investigate the role of additives on $\mathrm{WC}$ particle growth. Two different sizes of WC particles (avg. $200 \mathrm{~nm} \& 4.4 \mu \mathrm{m}$ ) were employed to examine the effectiveness of VC as a function of WC size and their contents. Based on XRD data and compositional analyses a mechanism for the inhibition of growth is proposed.

\section{Experimental Procedure}

Table 1 lists the manufacturers and specifications of the powders used in this study. The average sizes of the initial WC particles were about $200 \mathrm{~nm}$ and $4.4 \mu \mathrm{m}$. The powders were manufactured by OMG and Kennametal USA, respectively. The WC powders were mixed with ordinary Co, VC and additional carbon. The mixtures were milled for $10 \mathrm{hrs}$

Table 1 The size and manufacturer of powders used in this study.

\begin{tabular}{cccccc}
\hline & Size $(\mu \mathrm{m})$ & Manufacturer & & Size $(\mu \mathrm{m})$ & Manufacturer \\
\hline WC & 0.2 & OMG & Co & 1.4 & Kennametal \\
WC & 4.4 & Kennametal & VC & 0.98 & Kennametal \\
\hline
\end{tabular}


(a)

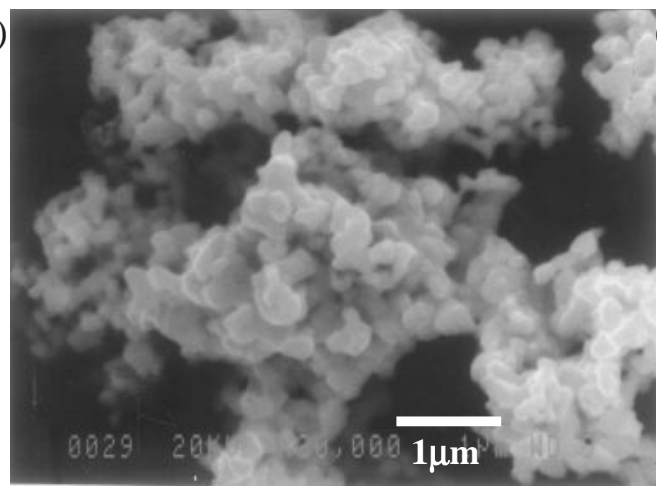

(c)

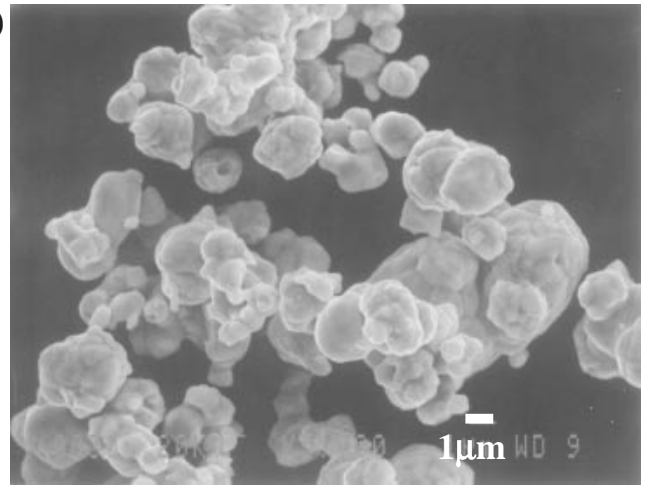

(b)

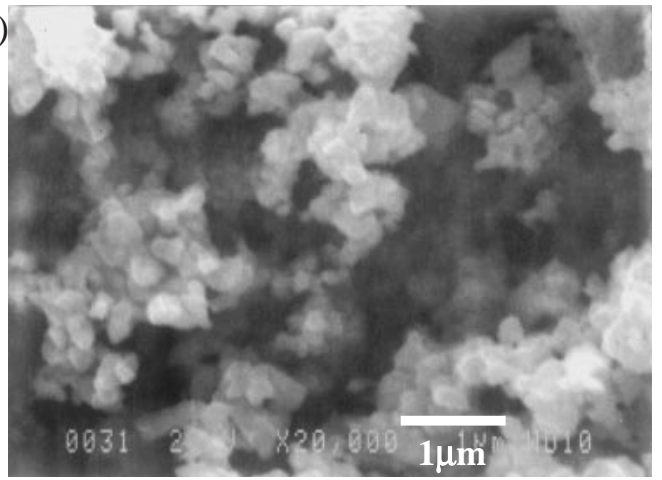

(d)

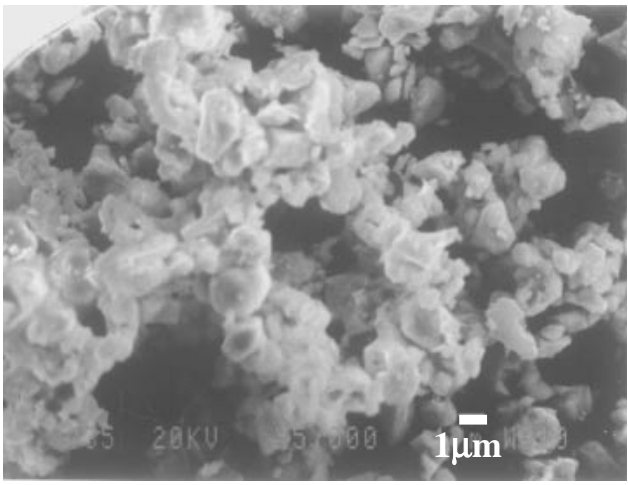

Fig. 1 Morphology of milled WC powders;(a) $200 \mathrm{~nm}$ raw WC, (b) $200 \mathrm{~nm}$ milled WC, (c) $4.4 \mu \mathrm{m}$ raw WC and (d) $4.4 \mu \mathrm{m}$ milled WC

using a planetary mill (Pulverisette5, FRITSCH, Germany) in ethanol at $250 \mathrm{~min}^{-1}$. For the milling process, $6 \mathrm{~mm}$ diameter WC-Co balls were used with a 10:1 ball to powder ratio.

VC was added in the range of about $0.2-2.0$ mass $\%$ and the quantity of Co binder was fixed at 10 mass $\%$. 0.4 mass $\%$ of carbon was added to each system. Specimens were fabricated through a conventional powder metallurgy $(\mathrm{P} / \mathrm{M})$ method with a compacting pressure of $200 \mathrm{MPa}$. Sintering was done in a graphite vacuum furnace at $1450^{\circ} \mathrm{C}$ and $1.33 \mathrm{~Pa}$ for $1 \mathrm{~h}$. The sintering temperature was chosen in order to compare the relative effectiveness of $\mathrm{VC}$ in the two different $\mathrm{WC}$ size systems.

XRD, TEM, SEM and EDS were employed for microstructure and phase analysis. Pure elemental Si was used as an XRD standard to ensure the accuracy of the analysis. The scanning rates for the XRD peak and decomposition analysis were fixed at $5^{\circ} / \mathrm{min}$ and $0.2^{\circ} / \mathrm{min}$, respectively. Prior to the analyses, specimens were polished to $0.1 \mu \mathrm{m}$ with a diamond slurry. They were etched for 2 minutes with a Murakami aqueous solution and then re-etched for 1 minute with an aqueous solution of $\mathrm{FeCl}_{3}$. Microstructures were examined by SEM (JSM-5600, JEOL, Japan), FESEM (Field emission SEM; JSM-6330F, JEOL, Japan), and HREM (high resolution electron microscopy, JEM-3000F, JEOL, Japan). XRD (M18XHF-SRA, MAC Science Co., Japan) and an Image analyzer (BMI-plus, Winatech, Korea) were used for the phase analysis and the measurement of particle size, respectively.

\section{Results}

\subsection{Microstructures}

Figure 1 shows the morphology of WC powders before and after milling. The powders, in the form of agglomerates, maintained a similar morphology. Using the full width half maximum (FWHM) technique by XRD, the size of the WC particles in the $200 \mathrm{~nm}$ system was determined to be 84 and $61 \mathrm{~nm}$ for the particles before and after the milling process, respectively. Figure 2 shows SEM micrographs of the WC$10 \mathrm{Co}-0.4 \mathrm{C}$ system with/without VC addition. The WC $(200 \mathrm{~nm})-10 \mathrm{Co}-0.8 \mathrm{VC}-0.4 \mathrm{C}$ system retained its size after sintering at $1450^{\circ} \mathrm{C}$ in the range of $100 \mathrm{~nm}-1 \mu \mathrm{m}$. An image analysis showed the average size of the WC particles to be about $300-400 \mathrm{~nm}$. It is apparent from Figs. 2(a) and (c) that added $\mathrm{VC}$ reduces the grain growth of WC. The effect of VC on growth inhibition was found to be, more or less, uniform throughout the microstructure.

In a separate study, the microstructures of WC $(200 \mathrm{~nm}$ or $4.4 \mu \mathrm{m})-10 \mathrm{Co}-0.5 / 1.0 \mathrm{VC}$ without the addition of extra carbon were found to retain a large volume of $\eta$ phase, $\mathrm{Co}_{6} \mathrm{~W}_{6} \mathrm{C}$ or $\mathrm{Co}_{3} \mathrm{~W}_{3} \mathrm{C}$. In particular, the system with $200 \mathrm{~nm}$ WC shows more $\eta$ phase in the raw powders and sintered specimens than the $4.4 \mu \mathrm{m}$ WC system. It is a well-known fact that the $\eta$ formation is facilitated in a carbon deficient system. ${ }^{17)}$ Table 2 shows that the loss of carbon from the $200 \mathrm{~nm}$ WC system is more than twice that from the $4.4 \mu \mathrm{m}$ WC system. Thus, 0.4 mass \% of extra carbon was added to all systems in this study and as a result, the formation of $\eta$ phase in the microstructure was minimal.

The effectiveness of $\mathrm{VC}$ in inhibiting particle growth was investigated using the WC $(200 \mathrm{~nm}$ and $4.4 \mu \mathrm{m})-10 \mathrm{Co}-x \mathrm{VC}-$ 
Table 2 The loss content of carbon before and after sintering.

\begin{tabular}{ccccc}
\hline $\begin{array}{c}\text { Size of } \\
\text { WC }(\mu \mathrm{m})\end{array}$ & Additive & $\begin{array}{c}\text { Loss of } \\
\text { carbon }(\text { mass } \%)\end{array}$ & $\begin{array}{c}\text { Size of } \\
\text { WC }(\mu \mathrm{m})\end{array}$ & $\begin{array}{c}\text { Loss of } \\
\text { Additive }\end{array}$ \\
\hline 0.2 & $0.2 \mathrm{VC}$ & 0.86 & 4.4 & $0.2 \mathrm{VC}$ \\
0.2 & $0.5 \mathrm{VC}$ & 0.85 & 4.4 & $0.5 \mathrm{VC}$ \\
0.2 & $0.8 \mathrm{VC}$ & 0.82 & 4.4 & $0.8 \mathrm{VC}$ \\
0.2 & $1.0 \mathrm{VC}$ & 0.64 & 4.4 & 0.34 \\
0.2 & $2.0 \mathrm{VC}$ & 0.78 & 4.4 & 0.34 \\
0.2 & $5.0 \mathrm{VC}$ & 0.6 & 4.4 & 0.35 \\
\hline
\end{tabular}

(a)

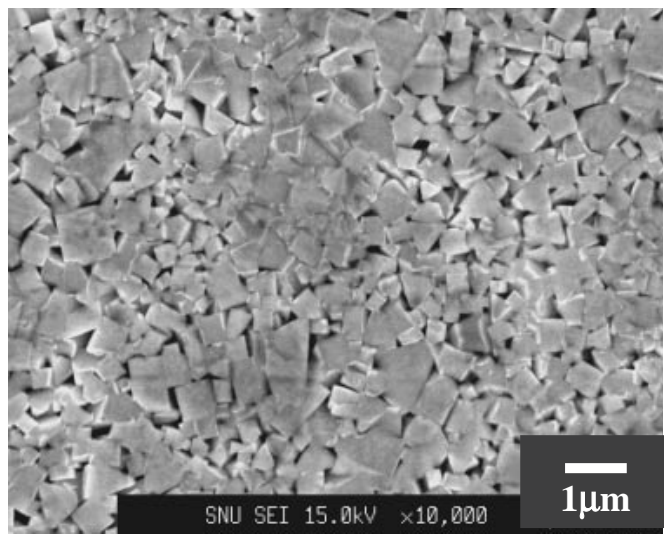

(b)

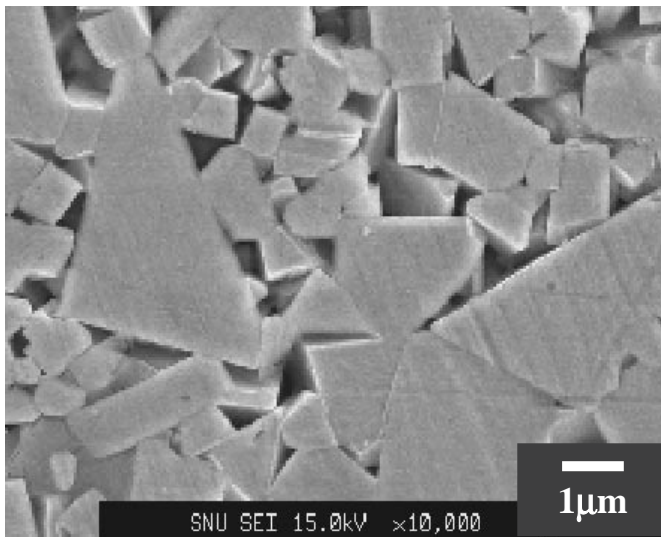

(c)

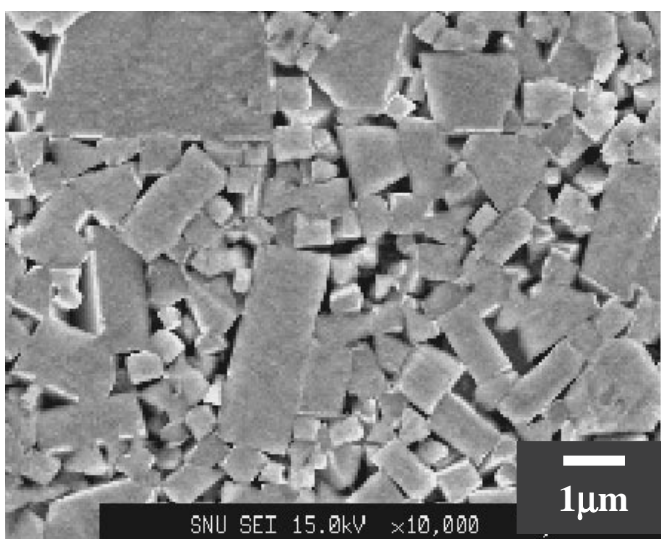

Fig. 2 Microstructures of (a) WC (200 nm)-10Co-0.8VC-0.4C, (b) WC $(4.4 \mu \mathrm{m})-10 \mathrm{Co}-0.8 \mathrm{VC}-0.4 \mathrm{C}$ and (c) WC $(200 \mathrm{~nm})-10 \mathrm{Co}-0.4 \mathrm{C}$. Specimens were sintered at $1450^{\circ} \mathrm{C}$ for $1 \mathrm{~h}$.

$0.4 \mathrm{C}$ systems. Figure 3 shows a plot of the average particle size of WC vs. VC content. The particle size decreases to a considerable extent with an increase in $\mathrm{VC}$ content. ${ }^{11)}$ In addition, a critical VC content $(0.5 \sim 1.0$ mass $\%)$ was required

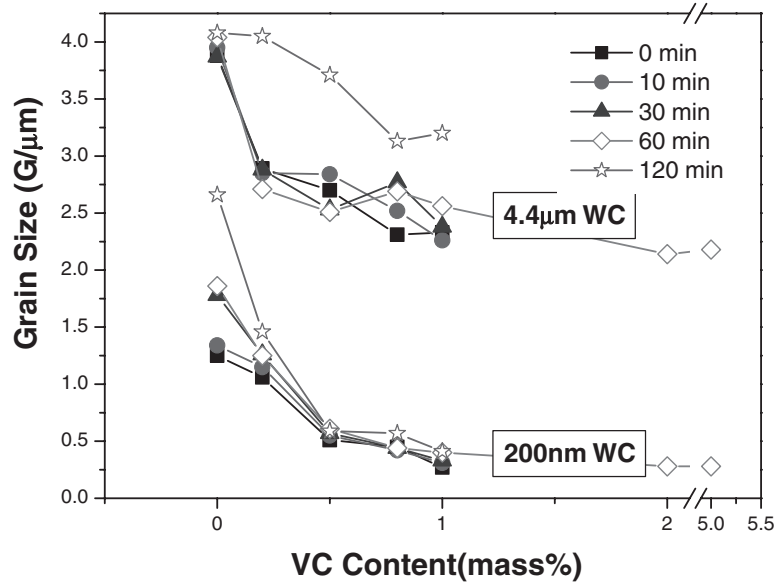

Fig. 3 Relationship between VC content and average particle size of WC. Specimens were sintered at $1450^{\circ} \mathrm{C}$ for various sintering time.

to achieve the full effect on the growth inhibition in both WC systems sintered at $1450^{\circ} \mathrm{C}$. WC particles reached a minimum as the $\mathrm{VC}$ content reached $\sim 2$ mass $\%$. However, the addition of $\mathrm{VC}$ at levels in excess of 1 mass \% in the WC-Co system led to the development of high porosity and $(\mathrm{V}, \mathrm{W}) \mathrm{C}$. The effectiveness of inhibition, calculated as a ratio of the final size of the $\mathrm{WC}$ with $\mathrm{VC}$ to that without $\mathrm{VC}$, was about the same for the two different WC size systems.

The data also indicate that changes in the average particle WC occur as a function of sintering time. The inhibition effect was apparent not only during the sintering stage at $1450^{\circ} \mathrm{C}$ but during initial heating stage as well. The size of average size of WC particles in WC $(200 \mathrm{~nm})-10 \mathrm{Co}-0.4 \mathrm{C}$ was about 5 times larger than that for WC $(200 \mathrm{~nm})-10 \mathrm{Co}-$ $1.0 \mathrm{VC}-0.4 \mathrm{C}$ when the specimens were simply heated to $1450^{\circ} \mathrm{C}$ and immediately cooled $(0 \mathrm{~min})$. In addition, a long sintering period $(120 \mathrm{~min})$ had no effect on the growth of WC for the systems with $0.5 \sim 1.0 \mathrm{VC}$. Most growth of WC, especially for both WC systems, occurred during the initial heating stage of sintering, presumably a liquid forming stage $\left(1350^{\circ}-1450^{\circ} \mathrm{C}\right)$. Contrary to this, the WC particles in the WC (200 nm)-10Co-0.4C system grew rapidly during both the initial heating and the sintering stages whereas little growth was detected in the WC $(4.4 \mu \mathrm{m})-10 \mathrm{Co}-0.4 \mathrm{C}$ during the sintering stage.

\subsection{XRD analysis}

In a preliminary XRD study the angles for the (001) peaks of raw $\mathrm{WC}$ powders were observed at $31.45^{\circ}$ and $31.50^{\circ}$ for $200 \mathrm{~nm}$ and $4.4 \mu \mathrm{m}$ WC. While, the (100) peaks appeared at $35.60^{\circ}$ and $35.66^{\circ}$ (star symbols in Fig. 4). The JCPDS (Joint 


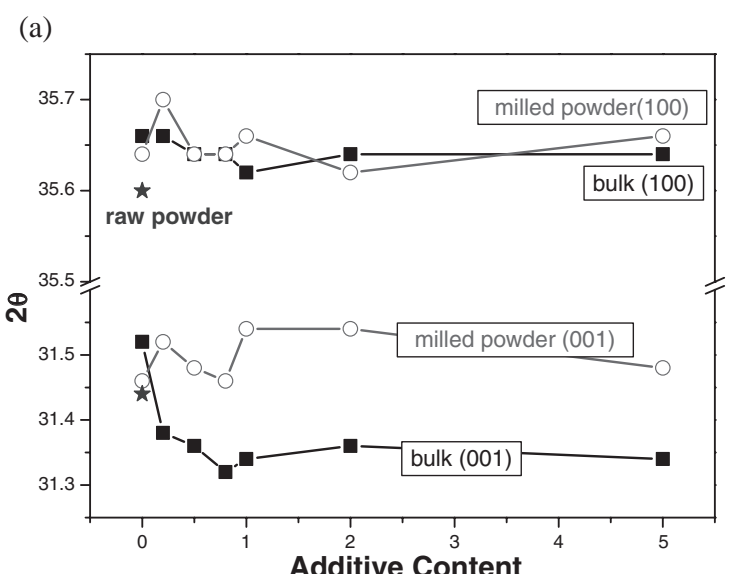

(b)

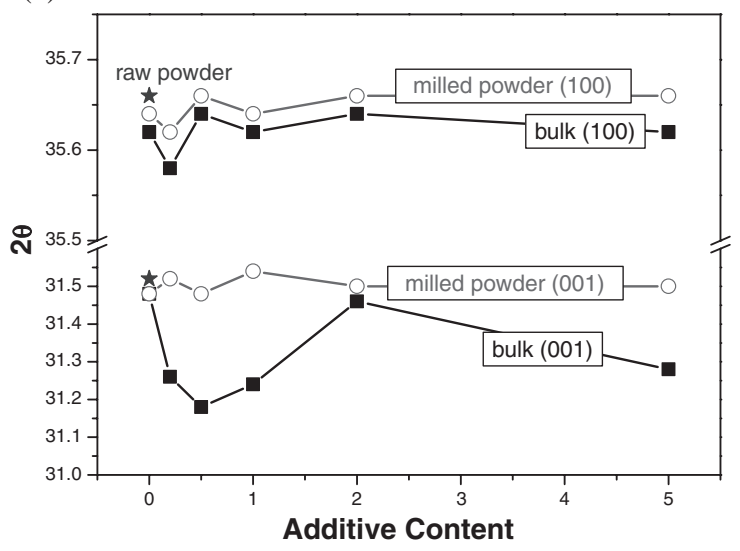

Fig. 4 The shifts in the main WC peaks such as (001) and (100) planes: (a) WC (200 nm)-10Co- $x$ VC-0.4C, (b) WC $(4.4 \mu \mathrm{m})-10 \mathrm{Co}-x \mathrm{VC}-0.4 \mathrm{C}$. Specimens were sintered at $1450^{\circ} \mathrm{C}$ for $1 \mathrm{~h}$.

Committee on Powder Diffraction Standards) data for diffraction angles $(2 \theta)$ of $\mathrm{WC}$ are $31.59^{\circ}, 35.74^{\circ}$ and $48.65^{\circ}$ for (001), (100) and (101) peaks, respectively. The major peaks tended to shift to lower angle positions, with a further decrease in WC particle size. This suggests an increase in lattice spacing, which can be attributed to differences in defect concentration and/or carbon stoichiometry between the two different WC crystallite sizes. ${ }^{6)}$ Therefore, an extensive XRD study was done with WC$10 \mathrm{Co}-x \mathrm{VC}-0.4 \mathrm{C}$ in order to examine the influence of $\mathrm{VC}$ in a WC-Co system.

The peak positions for WC in raw WC particles, milledpowder mixtures and sintered specimens are summarized in Fig. 4. From the WC-10Co- $0.4 \mathrm{C}$ system, different positions were noted for the (001) and (100) peaks corresponding to WC in the two WC systems. The (001) and (100) peak positions for all samples of WC (200 nm)-10Co-0.4C shifted to higher angles compared to those of raw WC (star symbols). The plot shows the changes in diffraction angles as a function of additive content. As the VC content increased, appreciable shifts in the (001) peaks took place to low angles. The shift of the (001) peak stopped when the VC content reached $\sim 1$ mass $\%$. The size difference of the WC particles caused a different level of peak shift. The angular shift of the (001) peak of $4.4 \mu \mathrm{m}$ WC system was twice that of the $200 \mathrm{~nm}$ WC system with respect to the positions of the WC-10Co-0.4C.

The decomposition of (101) peak of the WC phase was (a)

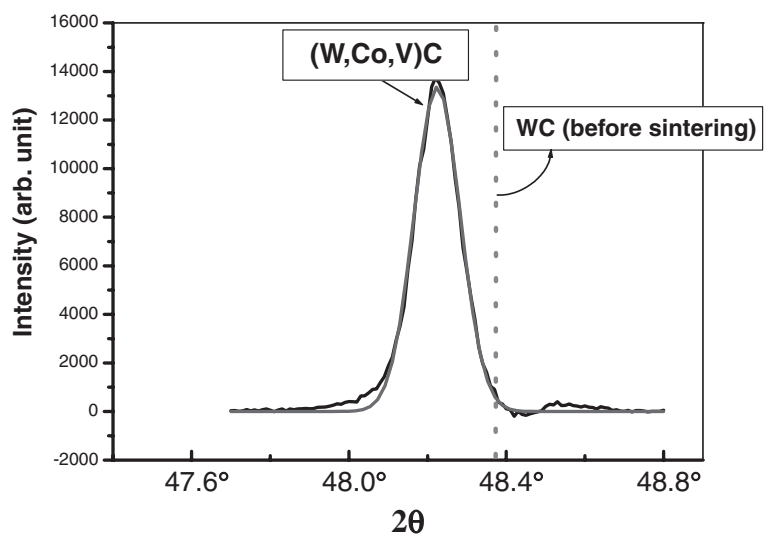

(b)

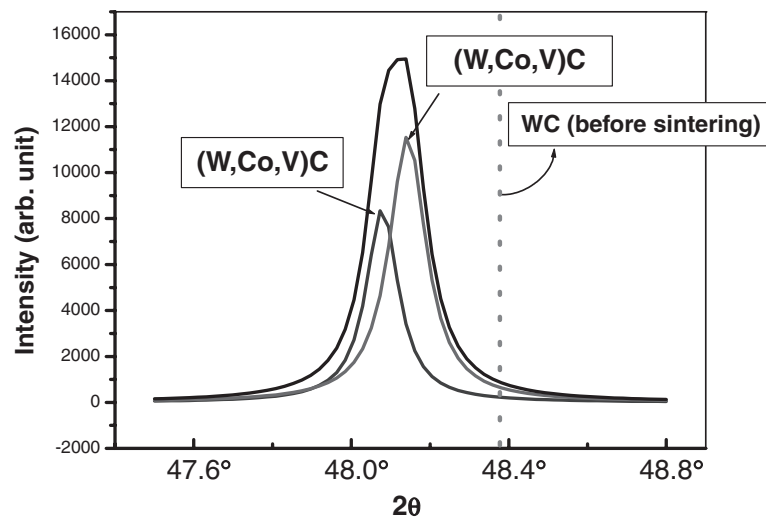

Fig. 5 Decomposition of WC (101) peak from the XRD profile of samples sintered at $1450^{\circ} \mathrm{C}$ for $120 \mathrm{~min}$ : (a) WC $(200 \mathrm{~nm})-10 \mathrm{Co}-0.8 \mathrm{VC}-0.4 \mathrm{C}$ and (b) WC $(4.4 \mu \mathrm{m})-10 \mathrm{Co}-0.8 \mathrm{VC}-0.4 \mathrm{C}$.

observed for the WC (200 nm and $4.4 \mu \mathrm{m})-10 \mathrm{Co}-0.8 \mathrm{VC}-0.4 \mathrm{C}$ systems sintered at $1450^{\circ} \mathrm{C}$ for $2 \mathrm{~h}$. A 2-h sintering period was used to obtain the full dissolution of $200 \mathrm{~nm} \mathrm{WC}$ for reprecipitation of the phase. Figure 5 shows that the peak for the $4.4 \mu \mathrm{m}$ WC system shifted to a low angle to a greater extent than that for the $200 \mathrm{~nm}$ WC system. The (101) peak for the $4.4 \mu \mathrm{m}$ WC system is composed of two peaks whereas that for $200 \mathrm{~nm}$ WC system is a single peak. On the other hand, a separate XRD measurement for WC-10Co-0.4C, which had been sintered at $1450^{\circ} \mathrm{C}$ for $0 \mathrm{~min}$, showed the peak shifts to be 48.218 and $48.216^{\circ}$ for the $200 \mathrm{~nm}$ and $4.4 \mu \mathrm{m}$ WC systems, respectively. This indicates that similar changes occurred, after the initial heating stage, in the WC phase of the two systems.

\subsection{HREM analysis}

HREM was performed for WC (200 nm)-10Co-0.8VC$0.4 \mathrm{C}$. The phase marked by an arrow in Fig. 6 is $\mathrm{VC}$, as evidenced by HREM/EDS. However, a continuous segregation of $\mathrm{VC}$ or $(\mathrm{V}, \mathrm{W}) \mathrm{C}$ at the $\mathrm{WC} / \mathrm{Co}$ interface was not observed. The microstructure did not reveal many steps, that have frequently been observed at the $\mathrm{WC} / \mathrm{Co}$ faceted interface by other researchers. ${ }^{16)}$ The abnormal growth of WC ( $>1 \mu \mathrm{m}$ in size) can be detected in the microstructure. EDS analysis in the vicinity of the interface is summarized in Fig. 7. The result shows, with limited accuracy, a negligible quantity of $\mathrm{V}$ is present inside the $\mathrm{WC}$ while $\mathrm{WC}$ contains 1.2 at $\%$ Co. Again, no preferential segregation of $\mathrm{V}$ was noted at the WC/Co interface. 
(a)

(b)

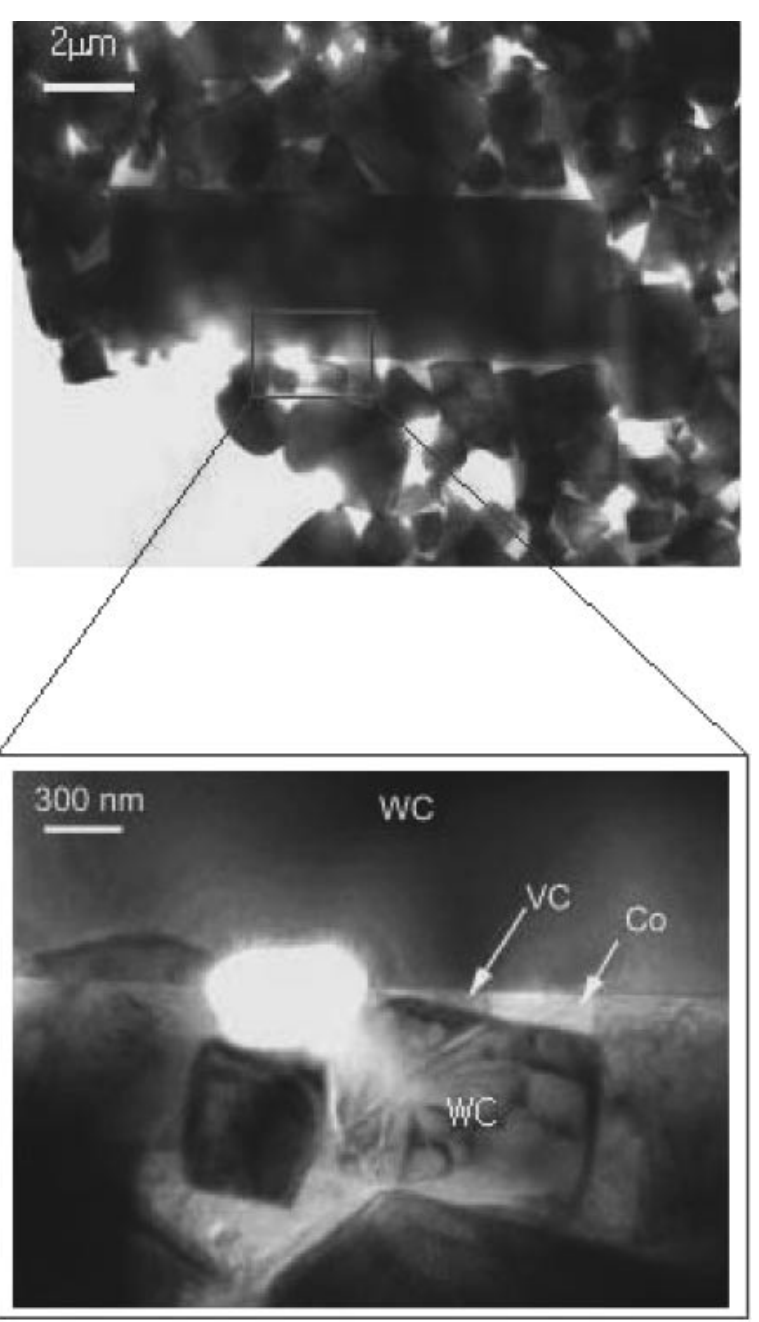

Fig. 6 TEM image of WC $(200 \mathrm{~nm})-10 \mathrm{Co}-0.8 \mathrm{VC}-0.4 \mathrm{C}$ : (a) a general microstructure at a low magnification and (b) a magnified view of (a). $\mathrm{VC}$ precipitate is observed at a WC particle junction.

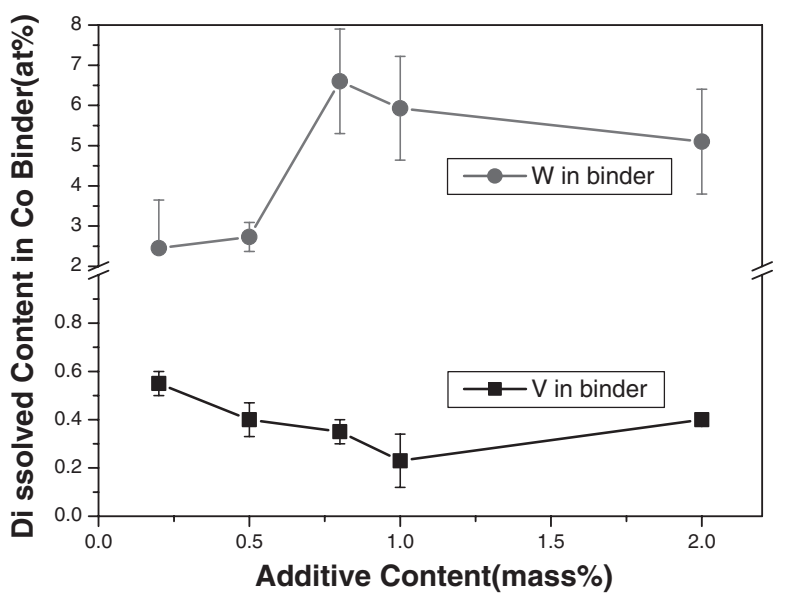

Fig. 7 Compositional analysis in the Co binder region of WC $(200 \mathrm{~nm})$ $10 \mathrm{Co}-x \mathrm{VC}-0.4 \mathrm{C}$ systems by TEM/EDS.

A compositional analysis was done for the Co binder region of the WC (200 nm)-10Co-0.8VC-0.4C system, using TEM/EDS. Each data point in Fig. 7 is the average of three measurements from different locations. It should be noted that the content of $\mathrm{W}$ and $\mathrm{V}$ in the $\mathrm{Co}$ binder changes inversely with respect to each other. The $\mathrm{V}$ content in the Co binder decreases with an increase in additive content up to $\sim 1$ mass $\%$ for the VC-containing system ${ }^{11)}$ and then, increases again. Interestingly, the inhibition effect is most prominent with $\sim 1$ mass $\%$ of $\mathrm{VC}$. The portion of $\mathrm{VC}$, which exceeds $\sim 1$ mass $\%$, is known to form $(\mathrm{V}, \mathrm{W}) \mathrm{C}$.

\section{Discussion}

\subsection{Formation of $(\mathrm{W}, \mathrm{M}) \mathrm{C}$-type Phase}

The existence of a large amount of $\eta$ phase in the $200 \mathrm{~nm}$ sized WC-Co systems, without extra carbon being added, was due to the large surface area available for oxidation and carbon loss. That is, carbon and surface oxygen escape from the system together in the form of $\mathrm{CO}$ during the heating and sintering process. Among the phases present in WC-10Co$x \mathrm{VC}-0.4 \mathrm{C},(\mathrm{V}, \mathrm{W}) \mathrm{C}$ in a cubic structure (B1) was detected by $\mathrm{XRD}$ with an increase in VC content (>1-2 mass\% VC). In addition to these phases, the results in Fig. 4 show that the WC phase is no longer the same as the raw WC. The (001) peaks of WC for all the sintered specimens have been significantly shifted to lower diffraction angles. This suggests that a $(\mathrm{W}, \mathrm{M}) \mathrm{C}$-type phase other than $\mathrm{WC}$ is formed in $\mathrm{WC}$ $10 \mathrm{Co}-x \mathrm{VC}-0.4 \mathrm{C}$ systems. That is, tungsten atoms in the $\mathrm{WC}$ of the HCP structure are partially replaced with other metal atoms such as $\mathrm{V}$ and Co. the solubility of Co in WC has been reported to be $\sim 0.5$ at $\%$ and $\mathrm{V}$ is insoluble in $\mathrm{WC}{ }^{18)}$

The initial peak shift of WC (200 nm)-10Co-0.4C to a high angle in Fig. 4 can be attributed to compositional variations (in $\mathrm{C}$ or $\mathrm{Co}$ ) or the removal of defects from WC during sintering. The effect of defects on peak shift can be ruled out since the removal of various defects causes the peak to move to low angles. The effect of Co is also ruled out because the presence of $\mathrm{Co}$ in $\mathrm{WC}$ causes an increase in the lattice spacing due to the expected repulsion among electronic structures. The results in Table 2 suggest that the shift to a high angle is due to the significant carbon loss in the $200 \mathrm{~nm}$ WC system.

In contrast, the WC $(4.4 \mu \mathrm{m})-10 \mathrm{Co}-0.4 \mathrm{C}$ system shows little change in the lattice spacing of the (001) plane. Moreover, an increase in (100) spacing was detected. This difference can be explained first by the minimized carbon loss and possibly by the newly formed $(\mathrm{W}, \mathrm{Co}) \mathrm{C}$. For the (W,Co)C phase, the $200 \mathrm{~nm}$-WC system produces more Cocontaining WC phase by rapid dissolution/reprecipitation than $4.4 \mu \mathrm{m}-\mathrm{WC}$ system. Figure 4 shows clearly that the addition of $\mathrm{V}$ to the WC $(200 \mathrm{~nm}$ and $4.4 \mu \mathrm{m})-10 \mathrm{Co}-x \mathrm{VC}-$ $0.4 \mathrm{C}$ systems increases the lattice spacing of WC. Then, the shift in the (001) peaks of both systems to low angles is attributed to the formation of $(\mathrm{W}, \mathrm{Co}, \mathrm{V}) \mathrm{C}$.

The V substitution in WC must have a significant effect on the lattice parameter of sintered specimens when the contribution of Co substitution is removed. The peak shift to a low diffraction angle indicates that the lattice spacing between the basal planes of WC increases as a result of the presence of $\mathrm{VC}$ in the system. This suggests that the formation of the $(\mathrm{W}, \mathrm{Co}, \mathrm{v}) \mathrm{C}$ phase, while not preferred, is unavoidable. This is important information concerning the role of $\mathrm{VC}$ in growth inhibition. The overall XRD results indicate that the presence of $\mathrm{V}$ results in the formation of the 
(W,Co,v)C phase.

The reliability level of the EDS analysis in Fig. 7 has not yet been determined. However, on the basis of a higher solubility of Co $(\sim 0.5$ at $\%)$ in WC than $\mathrm{V}(\sim 0$ at $\%)$, Co would be predicted to replace $\mathrm{W}$ in $\mathrm{WC}$ more readily than $\mathrm{V}$. The small amount of $\mathrm{V}$ entrapped in the precipitated $\mathrm{WC}$ seems to cause an expansion in the HCP structure of WC. The $\mathrm{XRD}$ analysis indicates that $\mathrm{V}$ is preferentially excluded during the WC phase precipitation and facilitates the formation of a $(\mathrm{V}, \mathrm{W}) \mathrm{C}$ cubic phase with $>1-2$ mass $\% \mathrm{VC}$.

It would be expected that the quantity of the $(\mathrm{W}, \mathrm{Co}, \mathrm{V}) \mathrm{C}$ phase is higher in a $200 \mathrm{~nm}$ WC system than in a $4.4 \mu \mathrm{m} \mathrm{WC}$ system due to the large surface area. That is, at a given VC concentration in liquid $\mathrm{Co}$, the $\mathrm{V}$ concentration in the $\mathrm{WC}$ phase would decrease with an increase in the amount of dissolved WC. This appears to be true for the WC $(4.4 \mu \mathrm{m})$ $10 \mathrm{Co}-<1.0 \mathrm{VC}-0.4 \mathrm{C}$ systems, which demonstrate a stronger influence of $\mathrm{V}$, higher peak shift, than the WC $(200 \mathrm{~nm})$ $10 \mathrm{Co}-x \mathrm{VC}-0.4 \mathrm{C}$. The $4.4 \mu \mathrm{m}$ WC system exhibited about twice the shift of the (001) peak than the $200 \mathrm{~nm}$ WC system.

This was reconfirmed with the result of the XRD decomposition study shown in Fig. 5. The (101) peak for the WC $(4.4 \mu \mathrm{m})-10 \mathrm{Co}-0.8 \mathrm{VC}-0.4 \mathrm{C}$ system is composed of two peaks. Those were determined to be $(\mathrm{W}, \mathrm{Co}, \mathrm{V}) \mathrm{C}$ at two different $\mathrm{V}$ concentrations. The reason for the two decomposed peaks is not currently clear. The system with $200 \mathrm{~nm}$ WC consists of a single phase of $(\mathrm{W}, \mathrm{Co}, \mathrm{V})$ due to the larger surface area of WC and extended dissolution time $(2 \mathrm{~h})$. The presence of $\mathrm{V}$ again increases the spacing between (101) planes in the system.

\subsection{Effect of VC on the solubility of $\mathrm{W}$ in Co}

The TEM/EDS results in Fig. 7 show that the presence of vanadium in the Co matrix has a negative influence on the solubility of $\mathrm{W}$ in the Co. That is, $\mathrm{W}$ has minus sign for its interaction coefficient in the Co melt with an increase in $\mathrm{V}$ content. ${ }^{19)}$ A positive sign for an interaction coefficient indicates the ease of dissolution in the presence of a second solute in a melt. Therefore, it can be said that the presence of $\mathrm{V}$ hinders the dissolution of $\mathrm{W}$ in the Co melt. The expansion in the lattice spacing in $(\mathrm{W}, \mathrm{Co}, \mathrm{V}) \mathrm{C}$ is consistent with the result shown in Fig. 7. Based on the XRD and TEM/EDS results, we propose this as a major reason for $\mathrm{V}$ or $\mathrm{VC}$ to inhibit the growth of WC in the WC-Co system.

It has been reported that VC inhibits WC growth by segregating around the WC particles. ${ }^{16)}$ However, it is not logical and not sufficient to explain the phenomenon based on segregated VC shown in Fig. 6. The precipitation (or segregation) of $\mathrm{VC}$, which was once in a complete liquid solution with WC and Co, occurs during cooling when the solubility of $\mathrm{VC}$ decreases in the Co melt. In the meantime, the growth of WC is known to occur during the initial heating stage. ${ }^{11)}$ Thus, the partial segregation of $\mathrm{VC}$ or $(\mathrm{V}, \mathrm{W}) \mathrm{C}$ observed in previous studies has little influence on the inhibition of WC growth. The uniform segregation of $\mathrm{VC}$ is also unlikely during the sintering stage when the additive contents are small $(<1$ mass $\%)$. The fact that $\mathrm{VC}$ or $(\mathrm{V}, \mathrm{W}) \mathrm{C}$ exists at the WC/Co interface, as reported by various HREM studies, does not adequately explain the growth inhibition mechanism.
A previous study ${ }^{11)}$ shows that the addition of VC to a WCCo system retards the densification process. The study reported that the major growth of nano WC occurred at the initial stage of sintering due to the coalescence of WC. Carbide or nitride systems such as TiC-Ni, TiN-Ni, and WC$\mathrm{Cu}$ are prone to particle coalescence. ${ }^{20)}$ However, WC-Co (micron size) is not known to show a notable coalescence and the coalescence results from the high surface energy between carbide (or nitride) and the liquid phase. ${ }^{20)}$

Although it is not clear at this point that coalescence is the cause of the initial WC growth, our study confirms that the major growth of WC occurs not only during the initial stage but during the sintering stage as well, provided no $\mathrm{VC}$ is present. In particular, the most effective role of $\mathrm{VC}$ in inhibiting WC growth was observed during the sintering stage. This must be related to a homogeneous distribution of $\mathrm{VC}$ (or V) in the Co at a higher temperature, effectively inhibiting the dissolution of W. Still, the segregation of VC is not sufficient, as an inhibition mechanism, to account for the growth inhibition at the initial stage of sintering.

\section{Summary and Conclusions}

WC-Co alloys of two different WC sizes $(200 \mathrm{~nm}$ and $4.4 \mu \mathrm{m})$ were investigated in conjunction with a growth inhibitor, VC. A significant loss of carbon occurred in all the sintered WC-Co alloys and this loss was intensified as the size of WC particles decreased. As a result, a large amount of $\eta$ phase was present in the $200 \mathrm{~nm}$ WC system unless extra carbon was added. The major peaks for raw WC tend to shift to lower angle positions with a decrease in particle size. This indicates an increase in lattice spacing, which is related to a low concentration of defects. Some of the conclusions of this study are summarized as follows.

(1). The (001) and (101) peaks of WC for all sintered specimens of WC-10Co- $x \mathrm{VC}-0.4 \mathrm{C}$ were shifted to lower diffraction angles, indicating that the lattice spacing between the corresponding planes increases as a result of the presence of VC. This increase in lattice parameters of $200 \mathrm{~nm} \mathrm{WC}$ system can be accounted for by the formation of $(\mathrm{W}, \mathrm{Co}, \mathrm{V}) \mathrm{C}$. (2). The major growth of WC occurs during the initial heating stage in a WC-Co system. However, the most effective role of $\mathrm{VC}$ in inhibiting WC growth was realized during the sintering stage due to the homogeneous distribution of VC (or V) in a Co melt.

(3). The presence of vanadium in the Co matrix was found to have a negative influence on the solubility of tungsten in Co. That is, the presence of $\mathrm{V}$ hinders the dissolution/reprecipitation of WC in the Co melt, resulting in less growth of WC than in systems without VC.

\section{Acknowledgements}

This work was supported by the Korea Research Foundation Grant (KRF-2001-013-E00116). Also, E. J. Lavernia wishes to acknowledge ONR support (Grants: N00014-01-10882 and N00014-00-1-0109). All authors are also thankful to Prof. Y. W. Kim at SNU for the help with HREM. 


\section{REFERENCES}

1) P. Schwarzkopf and R. Kiefer: Cemented Carbide; (Macmillan Co., NY 1960) pp.1-13.

2) N.C.Dent and R.J.Hosking: Powder Metall. 27 (1984) 14-18.

3) L.Zima: Int. J. of Powder Metallurgy and Powder Technology 18 (1982) 233-235.

4) L.Zima: Int. J. of Powder Metallurgy and Powder Technology 18 (1982) 237-241.

5) A. Nordgren and A. Melander: Powder Metall. 31 (1988) 189-200.

6) K.Jia, T. E. Fischer, and B. Gallois: Nanostructured Materials $\mathbf{1 0}$ (1998) 875-891.

7) Yu.V.Milman, S.Luycks and IT Northrop: Int. J. of Refractory Metals and Hard materials 17 (1999) 39-44.

8) G. Gille, B. Szesny, K. Dreyer, H. van den Berg, J. Schmidt, T. Gestrich and G. Leitner: Int. J. of Refractory Metals and Hard materials 20 (2002) 3-22.

9) W.D.Schubert, H.Neumeister, G.Kinger and B.Lux: Int. J. of Refractory Metals and Hard Materials 16 (1998) 133-142.

10) S.Imasato, K.Tokumoto, T.Kitada and S. Sakaguchi: Int. J. of
Refractory Metals and Hard Materials 13 (1995) 305-312.

11) Z.Fang and J.W.Eason: Int. J. of Refractory Metals and Hard Materials 13 (1995) 297-303.

12) F.Arenas, I.B. de Arenas, J.Ochoa and S.-A.Cho: Int. J. of Refractory Metals and Hard Materials 17 (1998) 91-97.

13) J.Zackrisson, B.Jansson, G.S.Uphadyaya and H.-O. Andren: Int. J. of Refractory Metals and Hard Materials 16 (1998) 417-422.

14) S.Luyckx, C. Osborne, L.A.Cornish and D. Whitefield: Powder Metall. 39 (1996) 210-212.

15) A. Jaroenworaluck, T.Yamamoto, Y.Ikuhara, T.Sakuma, T.Taniuchi, K.Okada and T. Tanase: J. Mater. Res. 13 (1998) 2450-2452.

16) S. Lay, S. Hamar-Thibault, and A. Lackner: Int. J. of Refractory Metals and Hard Materials 20 (2002) 61-69.

17) H.Suzuki: Bull. Jpn. Inst. Mat. (in Japanese) 11 (1972) 125-134.

18) T. B. Massalski: Binary Alloy Phase Diagrams, (ASM International, 2nd Ed., Materials Park, OH, USA 1990).

19) R. D. Pehlke and J. F. Elliot: Trans. Metall. Soc. AIME 218 (1960) 1088-1101.

20) M. Humenik and N. M. Parikh: J. Am. Ceram. Soc. 39 (1956) 60-64. 